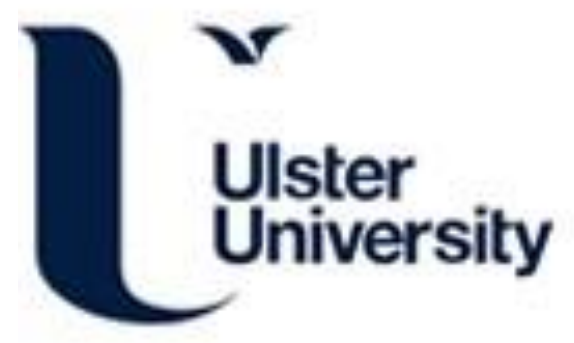

\title{
Socio-demographic, mental health and childhood adversity risk factors for self-harm and suicidal behaviour in College Students in Northern Ireland
}

O'Neill, S., Mc Lafferty, M., Ennis, E., Lapsley, C., Bjourson, AJ., Armour, C., Murphy, SD., Bunting, B., \& Murray, EK. (2018). Socio-demographic, mental health and childhood adversity risk factors for self-harm and suicidal behaviour in College Students in Northern Ireland. Journal of Affective Disorders, 239, 58-65. [JAD9849]. https://doi.org/10.1016/j.jad.2018.06.006

Link to publication record in Ulster University Research Portal

Published in:

Journal of Affective Disorders

Publication Status:

Published (in print/issue): 15/10/2018

DOI:

10.1016/j.jad.2018.06.006

Document Version

Author Accepted version

\section{General rights}

Copyright for the publications made accessible via Ulster University's Research Portal is retained by the author(s) and / or other copyright owners and it is a condition of accessing these publications that users recognise and abide by the legal requirements associated with these rights.

\section{Take down policy}

The Research Portal is Ulster University's institutional repository that provides access to Ulster's research outputs. Every effort has been made to ensure that content in the Research Portal does not infringe any person's rights, or applicable UK laws. If you discover content in the Research Portal that you believe breaches copyright or violates any law, please contact pure-support@ulster.ac.uk. 


\section{Accepted Manuscript}

Socio-demographic, mental health and childhood adversity risk factors for self-harm and suicidal behaviour in College Students in Northern Ireland

Siobhan O'Neill, Margaret McLafferty, Edel Ennis, Coral Lapsley, Tony Bjourson, Cherie Armour, Sam Murphy , Brendan Bunting, Elaine Murray

PII: S0165-0327(18)30524-X

DOI: 10.1016/j.jad.2018.06.006

Reference: $\quad$ JAD 9849

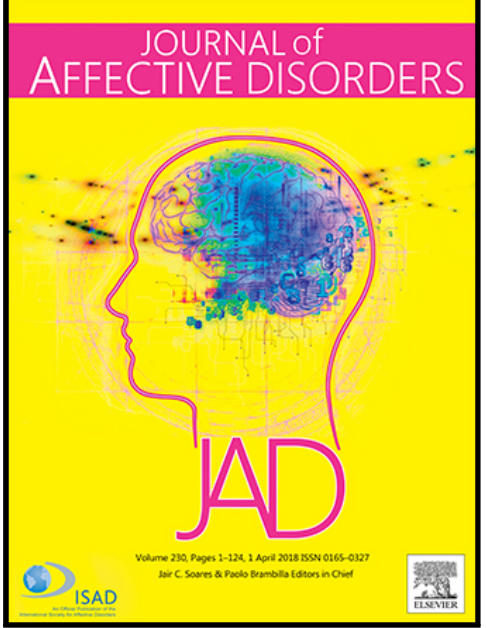

To appear in: Journal of Affective Disorders

Received date: $\quad 13$ March 2018

Revised date: $\quad 4$ May 2018

Accepted date: $\quad 1$ June 2018

Please cite this article as: Siobhan O'Neill, Margaret McLafferty, Edel Ennis, Coral Lapsley, Tony Bjourson, Cherie Armour, Sam Murphy, Brendan Bunting, Elaine Murray, Sociodemographic, mental health and childhood adversity risk factors for self-harm and suicidal behaviour in College Students in Northern Ireland, Journal of Affective Disorders (2018), doi: 10.1016/j.jad.2018.06.006

This is a PDF file of an unedited manuscript that has been accepted for publication. As a service to our customers we are providing this early version of the manuscript. The manuscript will undergo copyediting, typesetting, and review of the resulting proof before it is published in its final form. Please note that during the production process errors may be discovered which could affect the content, and all legal disclaimers that apply to the journal pertain. 
Highlights

- Thirty-one percent of students endorsed suicidal ideation

- almost 1 in 5 students made a plan for suicide in the 12 months prior to the survey

- Self-harm and suicidal behaviours were increased in non heterosexual individuals

- Self-harm and suicidal behaviours were increased with reported childhood adversities

- Probable alcohol dependence significantly increased likelihood of suicide attempt 
Title: $\quad$ Socio-demographic, mental health and childhood adversity risk factors for self-harm and suicidal behaviour in College Students in Northern Ireland

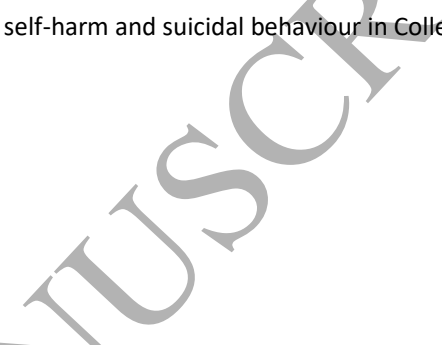

Authors: $\quad$ Siobhan $\mathrm{O}^{\prime}$ Neill $^{1}$, Margaret McLafferty ${ }^{1}$, Edel Ennis $^{1}$, Coral Lapsley ${ }^{2}$, Tony Bjourson ${ }^{2}$, Cherie Armour ${ }^{1}$, Sam Murphy ${ }^{1}$, Brendan Bunting $^{1}$ and Elaine Murray $^{2}$

Institution:

$1 \quad$ Psychology Research Institute, Ulster University, Coleraine Campus BT52 1SA

2 Northern Ireland Centre for Stratified Medicine, Ulster University, C-TRIC, Altnagelvin Hospital, Derry/Londonderry

Word count: 3096

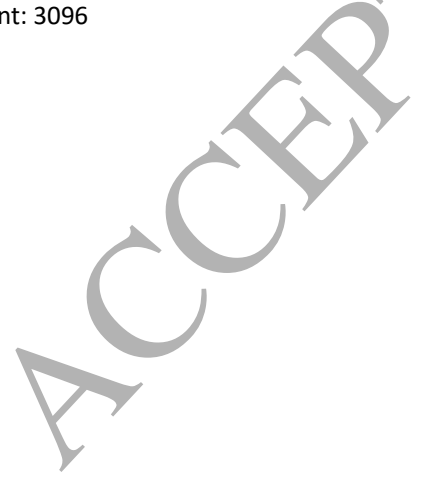




\section{Abstract}

Background: Prevalence estimates of suicidal behaviour in the college student population are consistently higher than rates for the general adult population. This study examines mental health disorders and childhood adversities as predictors of self-harm and suicidal behaviours.

Methods: The Ulster University Student Wellbeing study commenced in September 2015 as part of the WHO World Mental Health Surveys International College Student Project. In Northern Ireland (NI) 739 students participated (462 female, 274 male and 3 other specified), with the WMH-CIDI used to examine psychopathology. Mean age was 21 years old.

Results: Thirty-one percent endorsed suicidal ideation ( $24.3 \%$ of males and $36.9 \%$ of females) with almost 1 in 5 students having made a plan for suicide in the 12 months prior to the survey. Latent profile analysis revealed three profiles of childhood adversity (high, moderate, and low risk). Logistic regression analyses showed that there was an increased likelihood of all queried self-harm and suicidal behaviours in those who were not heterosexual orientation, and among those with either moderate or high levels of childhood adversities. Probable alcohol dependence was associated with a significantly increased likelihood of suicide attempt or self-harm with either a suicide plan or a suicide attempt.

Limitations: Influences of self-report measures and the generalizability of the sample are discussed.

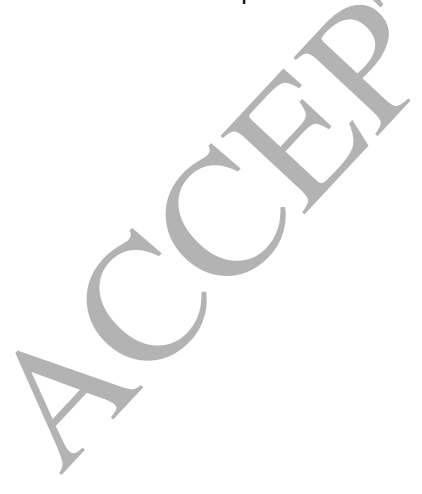


Conclusions: Policies and strategies for early identification of those with mental illnesses or adversities that increase their risk, should be prioritised. It would also be useful to identify individuals at risk in secondary schools to allow for additional support to be offered to them during the key time of transitioning into higher education.

Keywords: college students; suicidal behaviour; mental health; childhood adversities; LGBT

Suicide is the second leading cause of death among young people aged 15-29 years globally (World Health Organisation, 2017). Prevalence estimates of suicidal behaviour in the college student population are consistently high (Mortier et al., 2018, Mortier et al., 2017a; Mortier et al., 2017b; McLafferty et al., 2017). Self-harm is the strongest predictor of suicidal behaviour (Gunnell et al., 2008, Guan, Fox \& Prinstein, 2012, Scott et al., 2015, Ribeiro et al. 2016).

Suicidal behaviour also carries an array of adverse consequences including extreme psychological distress (Garlow et al. 2008), poor academic performance (De Luca et al., 2016; Mortier et al. 2015; Mortier et al., 2017b), reduced rates of professional help-seeking for mental health problems (Hom, Stanley \& Joiner, 2015) and various long-term adverse outcomes, such as persistent mental and physical health problems, unemployment, loneliness, and low life satisfaction (Goldman-Mellor et al., 2014). Suicidal behaviour in students has also been linked to sleep disturbance (Gangwisch et al., 2010; Becker

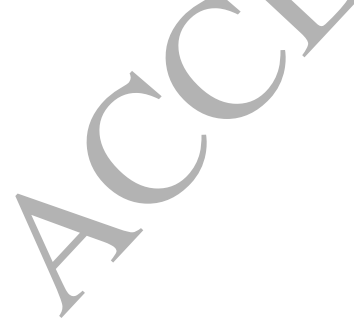


et al., 2018). There is some debate about what the term contagion means, and it has been studied in various contexts e.g. family /peer exposure, local society, and media exposure (Cheng, Li, Silenzio \& Caine, 2014). However, contagion has been linked to vulnerability to suícidal behaviour (Chan et al., 2018), with depressive affect mediating susceptibility (Ma-Kellatns, Back \& Or, 2018).

The link between mental illness and increased risk of suicidal thoughts and behaviours is well documented (Franklin et al., 2017; O'Connor \& Nock, 2014). The first symptoms of mental disorders typically emerge in adolescence (Auerbach et al., 2016) and this may be related to the neurological changes that are occurring at this stage of development (Giedd et al., 2008; Paus et al., 1999). Studies of university populations demonstrate high rates of mental illness, often with low rates of treatment (Eisenberg et al., 2013; Mortier et al., 2015; Auerbach et al., 2016; Auerbach et al., 2018). The first paper from this research study showed that more than half of new undergraduate students reported any lifetime disorder and co-morbidity was common with $19.1 \%$ of students experiencing three or more disorders. (McLafferty et al., 2017)

Several studies worldwide have also show higher rates of suicidal behaviour and mental illness in those of a sexual minority status (nonheterosexual) (Herek et al., 2007; Hatzenbuehler et al., 2011; Mortier et al., 2018). A recent study found that $46.9 \%$ of LGBT people had thought about suicide, $35 \%$ had self-harmed, and a quarter had attempted suicide ( $\left.\mathrm{O}^{\prime} \mathrm{Hara}, 2013\right)$. Suicidal thoughts and behaviour in this group were more frequent and lasted longer than for the general population (O'Doherty, 2016). Suicidal behaviour has also been shown to be associated with exposure to childhood adversities, especially intrusive or aggressive adversities (Bruffaerts et al., 2010; O'Connor \& Nock, 2014; McLafferty et al., 2016). Indeed, physical and

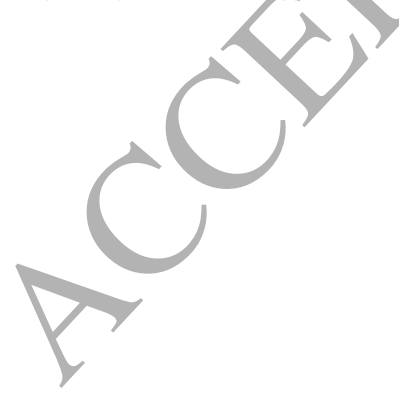


sexual abuse have been found to be some of the strongest predictors of suicidal behaviour (Bruffaerts et al., 2010). Furthermore, as the number of childhood adversities increase so too does suicidal behaviour (O'Connor \& Nock, 2014).

College life is itself also associated with many factors that correlate with high risk of mental illness and suicidal behavior. The student may need to manage changed financial circumstances, including living on a greatly reduced income or taking out loans for the first time (e.g. to meet high costs of living or tuition fees (Universities UK, 2015)). Financial strain and debt, and more specifically the degree to which United Kingdom (UK) University students are concerned about their financial strain and debt is associated with poor mental health and poor academic performance (Richardson, Elliott, Roberts \& Jansen, 2017), particularly among those with poor emotional functioning (Sadeghi Bahmani et al., 2018). Leaving the family home for the first time also means lessened parental oversight, which can bring new opportunities to experiment with alcohol and other substances and form sexual relationships (Cleary, Walter \& Jackson, 2011).

Whilst being well educated may confer protection from mental illness and suicidal behaviour generally (O’Connor \& Nock, 2014), student life is increasingly competitive. Students have the stress of needing to meet academic standards whilst learning through new less structured methods (Cleary et al., 2011). Students themselves may well have high levels of social perfectionism (Kearns, Forbes, Gardiner \& Marshall, 2008), which correlates with an increased risk of suicidal behaviour (O'Connor \& Nock, 2014). Together these conditions create an environment that may increase the likelihood self-harm and suicidal behaviour among those who are vulnerable

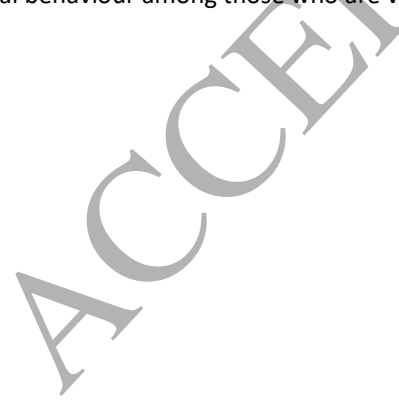


In Northern Ireland (NI) the rates of mental disorders are $25 \%$ higher than other parts of the UK (Department of Health, Social Services and Public Safety, 2014). Indeed, prevalence estimates are amongst the highest worldwide, and are the highest of Western European countries (Bunting, Murphy, O'Neill \& Ferry, 2012). At 16 suicides per 100,000 (Northern Ireland Statistics and Research Agency (NISRA), 2017) the suicide rates in NI are higher than in the other UK regions, and whilst there is a general trend towards a decline in suicide rates in the UK and Ireland, in NI the rates have increased steadily in the last 10 years (Samaritans, 2017).

The legacy of the years of conflict in NI known as the "Troubles", has impacted on the rates of mental illness in NI (Bunting, Murphy, O'Neill \& Ferry, 2013, O'Connor \& O'Neill, 2015) and there are concerns about the transgenerational impact of the Troubles on today's young people (O'Connor \& O'Neill, 2015). The "Troubles" refers to many years of civil conflict between paramilitary organisations who supported the return of NI to Ireland, and the British security forces. The 30-year period from 1968 to 1998 saw almost 4,000 deaths, 48,000 physical injuries, 34,000 shootings and 14,000 bombings (Fay et al., 1997; Daly, 1999).

Around one in 10 adolescents in NI have engaged in self-harm, and again, Troubles exposure was associated with a higher risk ( $\mathrm{O}^{\prime}$ Connor et al., 2014). Hate crime against the LGBT community in NI is also noted to be a legacy of the Troubles, with the prevalence of such incidences increasing in recent years (O'Neill et al., 2015). The NI population in general report high levels of childhood adversities and these themselves are associated with increased risk of mental illness and suicidal behaviour (McLafferty et al., 2016).

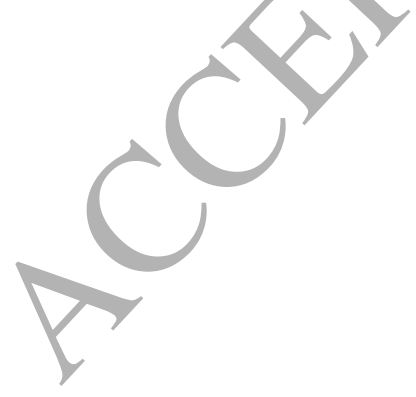


Countries invest heavily in college students, and yet this is a key time for the development of suicidal behaviour, associated with mental illness, academic dropout and underachievement, as well as an increased risk of suicide. There is a clear need for an increased understanding of the risk factors for suicidal behaviour and self-harm in students in NI so that we can develop ways of identifying those at risk and better meet their needs, and develop policies and strategies to reduce risk in this group. It is also important to examine whether membership of certain subgroups is associated with an increased likelihood of suicidal thoughts and behaviours.

A recent meta-analysis of 36 studies of college students revealed lifetime rates of suicidal ideation of 22.3\% (Mortier et al., 2017b). In NI, rates from the initial analysis of the Ulster University Student wellbeing study revealed higher lifetime suicidal ideation rates of $31 \%$ and 12 month rates of $18.3 \%$, with a mean age of onset of 15.7 years (McLafferty et al., 2017). However, there is limited data on suicidal behaviour in this group, particularly in the early stages of entry to university. This study addresses that gap by testing hypotheses that mental illness, childhood adversities and sexual orientation may be associated with rates of self-harm and suicidal behaviour in this student group.

The World Mental Health International College surveys (WHO, 2015) note that it is important to study college students at entry point and follow them longitudinally across their studies. This contributes towards the overall aims of identifying high risk groups of students and targeting early low cost and easily disseminated internet based interventions before crises situations emerge (Auerbach et al., 2018; Mortier et al., 2018; WHO, 2015). This will hopefully optimise the university experience for the student (Auerbach et al., 2018; Mortier et al., 2018; WHO, 2015).

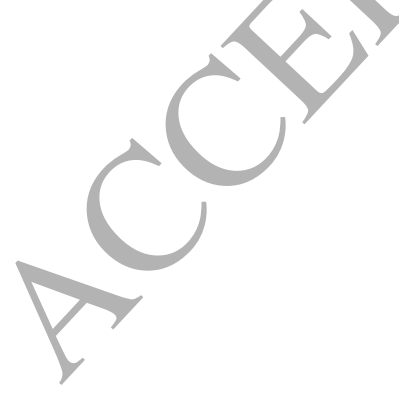


Design

Method

The Ulster University Student Wellbeing study (UUSWS) from which this paper is drawn, was part of the World Mental Health International College Student Project (World Health Organisation (WHO), 2015) The data was gathered in September 2015 across four campuses of Ulster University in NI. Ethical approval was obtained for the NI study from the Ulster University Research Ethics Committee (REC/15/0004).

Sample

One week prior to registration, prospective students were emailed the participant information sheet outlining the study. Trained researchers recruited students on the various campuses after they completed the registration process. Students were provided with a card containing their unique ID number and a link to the survey, which was also emailed to them as a reminder. The survey instrument was administered on-line using Qualtrics software.

The participants were 739 students (female, $n=462$; male, $n=274$; transgender female, $n=1$; transgender male, $n=1$; non-binary, $n=1$ ). Participants were aged 18-49 years with an average age of 21 years $(M=20.69, S D=5.313)$. Overall, 669 students identified as heterosexual, while 66 identified as non-heterosexual.

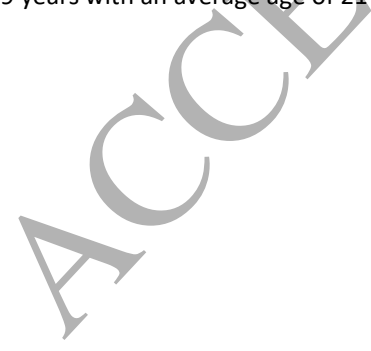


This latter category will be referred to as sexual minority status. In relation to socio-economic status, $6.9 \%$ were poor, $55.8 \%$ had enough but not much extra, $35.1 \%$ were comfortable and 3.1\% were well-to-do. Participants were residents of the United Kingdom (UK) or the Republic of Ireland (ROI), with 98.2\% of participants identifying as white. Students under 18 or repeating first year and international students were excluded from participating. The completed response rate was $16.95 \%$ in relation to the total number of first year students registered.

Materials

Diagnostic Assessment

In keeping with the WMH-ICS surveys, the prevalence of mental disorders was assessed using an adapted version of the WMH Composite International Diagnostic Interview (CIDI), version 3.0 (Kessler \& Ustun, 2008) which explores the prevalence of mental health problems in accordance with ICD and DSM criteria. The instrument includes screening sections for depression, bi-polar disorder, anxiety disorders and other serious emotional problems. Good concordance has been found between the WMH-CIDI and clinical assessments (Haro et al., 2006). Although the methodology allowed the assessment of a variety of mental health disorders, self-report methods do not lend themselves to the assessment of psychotic disorders. For this reason, their prevalence was not considered in the current survey.

Again, following the WMH-ICS protocol, the Alcohol Use Disorders Identification Test (AUDIT) (Saunders et al., 1983) was used to assess alcohol dependence. Across the WMH LCS, the version of the AUDIT used defined alcohol use disorder as either a total score of 8+ or a score of 4+ on the AUDIT

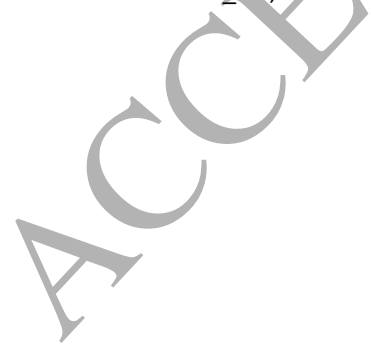


dependence questions (Babor, Higgins-Biddle, Saunders \& Monteiro, 2001). Although not a diagnostic tool, the AUDIT has good concordance with clinical diagnoses (Reinert \& Allen, 2002) and as such is used as a measure of the presence versus absence of an alcohol use disorder (Auerbach et al., 2018).

\section{Suicidal behaviours}

Suicidal thoughts, plans and attempts (both lifetime and within the past 12 months) were assessed using items from the Self-Injurious Thoughts and Behaviour Interview (SITBI) (Nock, Holmberg, Photos \& Michel, 2007). The instrument has good psychometric properties in terms of both reliability and validity (Nock et al., 2007). Information about support resources was provided to all participants the end of the survey and the university counselling services were alerted if a participant indicated that they had attempted or planned suicide in the previous year. These participants were contacted and assessed by trained counsellors. In this analysis suicidal behaviours were grouped as ideation, plans or attempts following the procedure of Nock et al. (2007). Information about support resources was provided to all participants the end of the survey and the university counselling services were alerted if a participant indicated that they had attempted or planned suicide in the previous year. These participants were contacted and assessed by trained counsellors.

Non-suicidal self-injury (self-harm)

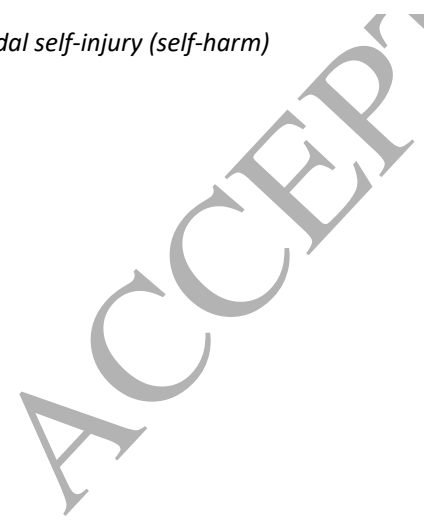


NSSI was assessed using items from the well-validated Self-Injurious Thoughts and Behaviors Interview (SITBI; Nock et al., 2007). Students were asked: "Did you ever do something to hurt yourself on purpose, without wanting to die (e.g., cutting yourself, hitting yourself, or burning yourself)?" Prevalence in the 12 months prior to college entry was also assessed. Lifetime self-harm rates were categorised as (1) experimental (1-2 tim 12 months prior to college entry was also assessed. Lifetime self-harm rates were categorised as (1) experimental (1-2 times), low (3-10 times), high (11-30 times) and very high (over 30 times) (Nock et al., 2007).

\section{Childhood adversities}

In the current study 13 adverse childhood experiences were analysed; serious parental mental health problems, parental alcohol or drug problems, parental suicidal behaviour, parental involvement in criminal activity, domestic violence, physical punishment, physical abuse, insults received repeatedly, emotional abuse, inappropriate touching, sexual abuse, serious neglect, doing chores which were dangerous or age inappropriate. Parental mental health problems and substance disorders were measured using questions developed for the Army STARRS project (Army STARRS; Ursano, Colpe, Heeringa, Kessler, Schoenbaum, \& Stein, 2014). Parental suicidal behaviour and criminal activity, childhood neglect and hard chores were measured using an adapted version of the childhood section of the WMH-CIDI (Kessler \& Üstün, 2004). Domestic violence, physical punishment and physical abuse, insults received repeatedly, and emotional abuse, inappropriate touching and sexual abuse were measured using questions adapted from the Adverse Childhood Experiences Scale (Felitti et al. 1998). Good concordance has been found between the WMH-CIDI and clinical assessments (Haro et al., 2006).

Sexual orientation

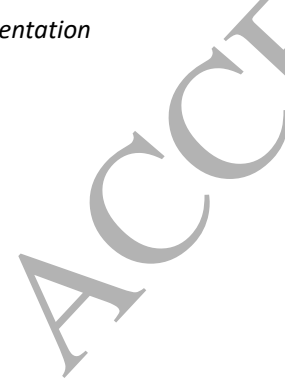


Sexual orientation was assessed by asking participants if they were heterosexual or straight, gay or lesbian, bisexual, asexual, not sure or other (free response). Participants were coded in the current study as sexual minority status if they did not indicate that they were heterosexual or straight.

\section{Data Analysis}

Descriptive statistics were calculated for self-harm and suicidal thoughts and behaviors by gender. Weights were created using the gender and age characteristics of the first year student population at Ulster University. Subsequently these were applied to analyses to ensure that the study results were representative of the student population. Latent Profile Analysis (LPA) was used to identify underlying childhood adversity profiles. A range of model fit indices were used to compare competing models, with lower AIC, BIC and SSABIC and an entropy value closest to 1 indicative of the optimal number of classes. Logistic regression analyses identified risk factors for suicidal behaviour and self-harm, with a number of predictor variables entered simultaneously into each model. Significant values of ${ }^{*} p<.05, * * p<.01, * * * p<.001$ are included. All analyses were conducted using SPSS (version 23) and Mplus version 7.31, (Muthén \& Muthén, 1998-2012).

\section{Results}

The prevalence rates for suicidal ideation and behaviour by gender, and also suicide plans and behaviour among those with suicidal ideation in the previous 12 months are presented in table 1 . Thirty-one percent endorsed suicidal ideation ( $24.3 \%$ of males and $36.9 \%$ of females) with almost 1 in 5 students having made a plan for suicide in the 12 months prior to the survey $(19.6 \%, 16.5 \%$ of males and $21.6 \%$ of females). The rates for 12 month attempt were $5.5 \%$ for

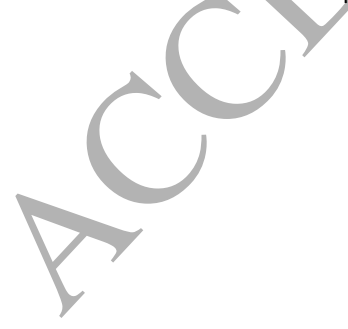


males and $9 \%$ of females ( $7.7 \%$ overall). Of those who endorsed suicidal ideation, $12.1 \%$ reported having a suicide plan and $4.3 \%$ reported having a suicide attempt. $8.2 \%$ of those with suicidal ideation in the past 12 months reported a suicide attempt.

[Insert Table 1 about here]

Table 2 illustrates the lifetime prevalence rates for self-harm and suicidal ideation and behaviour by gender. The self-harm question was endorsed by 151 participants. Of these, 122 also reported suicidal ideation. A suicide plan was reported by 91 of these, whilst a suicide attempt was reported by 43 of them. [Insert Table 2 about here]

Table 3 illustrates the prevalence rates of number of times these participants engaged in self-harm. Results showed that low self-harm (3-10 times) was most common at 7.5\%, followed by experimental self-harm (1-2 times) at 5.1\%. However, high self-harm (11-30 times) and very high self-harm (more than 30 times) were both quite prevalent at $2.9 \%$ and $4.1 \%$ respectively.

\section{Latent Profile Analysis (LPA) of adverse childhood experiences}

[Insert Table 3 about here]

LPA assessed the co-occurrence of 13 adverse childhood experiences including parental maladjustment and maltreatment. A series of models were specified and estimated using Mplus version 7.31. The fit indices for the LPA are shown in table 4. The fit indices were examined to establish the optimal

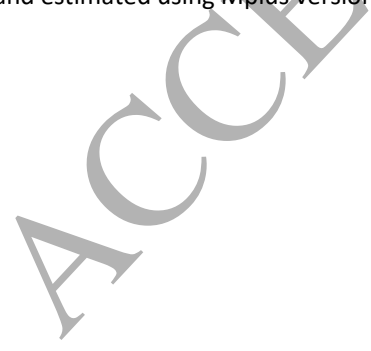


number of classes. The three class solution was determined to be the best model based on lower AIC, BIC and SSABIC values for the three-class model in comparison to either the one or two class models. Moreover, while the fit indices for the four-class model were also lower, the number of people in this four class model was very low, at less than $1 \%$ of the sample, Therefore the 3 class model was also determined to be optimal on the basis of parsimony. Furthermore, the entropy value for the three class model was good at .994 .

\section{[Insert Table 4 about here]}

Figure 1 shows the latent profile plot for the three class model. Class 2 accounted for $87.1 \%$ of the sample and was considered the baseline, low risk class because it was characterised by low levels of adversity. Class 1 was labelled the moderate risk class and consisted of $10.4 \%$ of the sample. Class 3 accounted for $2.5 \%$ of the sample. Individuals in this "high risk" class endorsed the highest levels of early adverse experiences, particularly those related to maltreatment such as family violence, physical punishment and physical abuse as well as emotional abuse and neglect.

\section{[Insert Figure 1 about here]}

Table 5 illustrates the logistic regression analyses of demographic and childhood adversity correlates of suicidal behaviour and self-harm. Females had a significantly increased likelihood of both self-harm and suicidal ideation. There were no gender differences in the other measures of self-harm and suicidal behaviour. Those aged 21 and over were significantly more likely to have made a suicide attempt. There was an increased likelihood of all the self-harm and suicidal behaviours in those who were sexual minority status, and among those with either moderate or high levels of childhood adversities.

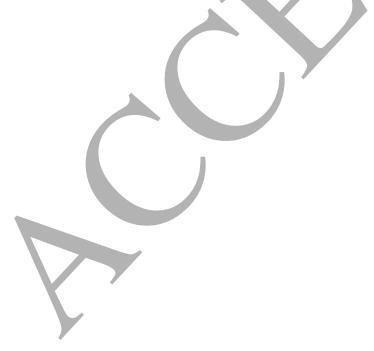


[Insert Table 5 about here]

Table 6 illustrates the logistic regression analyses of mental health and substance correlates of suicidal behaviour and self-harm. Lifetime mood disorders and lifetime GAD significantly increased the likelihood of all self-harm and suicidal behaviours. Alcohol dependence was associated with a significantly increased likelihood of suicide attempt, or self-harm with either a suicide plan or a suicide attempt.

[Insert Table 6 about here]

\section{Discussion}

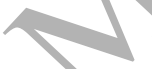

This study demonstrated that rates of suicidal behaviour in first year college students in NI are high, with almost a third of participants having thought about suicide at some stage, $12.1 \%$ in the past 12 months, and almost 1 in 5 reported having made a plan for suicide in the 12 months prior to attending university. The rates for suicide attempt in the year prior to commencing university were also high at $7.7 \%$, with almost one in 10 females reporting an attempt. These figures are further evidence of the effects of the stress experienced by young people in this time of transition and support the need for interventions to identify young people who may have suicidal thoughts and provide help.

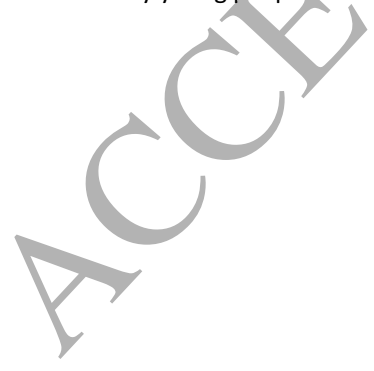


The fact that $12.1 \%$ of those with ideation had a suicide plan, and $8.2 \%$, a suicide attempt, demonstrates the importance of offering services and treatments to all those with suicidal thoughts. This is also in keeping with the National Institute for Health and Care Excellence (NICE,2011) guidance on risk assessment, recommending that risk scales should not be used to identify who should receive suicide prevention treatments, and that suicide prevention interventions should be offered to all those who report suicidal thoughts. The rates of self-harm in this population are also high (19.6\%). These are comparable to the findings from other studies in American colleges (approx. 25\%) (Mortier et al., 2017b), Irish colleges (Dooley \& Fitzgerald, 2012), and in the UK (Borrill, Fox, Flynn \& Roger, 2009). As consistently shown (Mortier et al., 2017b), females had a significantly increased likelihood of both self-harm and suicidal ideation. Interestingly, in contrast to the predominant evidence (Mortier et al., 2017b), this study showed no female predominance in the likelihood of suicide plans or attempts. It must also be remembered that men in NI are more likely than women to have only one suicide attempt that ends in death (O'Neill et al., 2014). Therefore, there is a need to ensure that both female and male students have access to suicide prevention services.

Self-harm is a functional, learned behaviour used to self-regulate in the face of stress with an array of correlates that are also associated with suicidal thoughts and death by suicide (Nock and O'Connor, 2014). A recent study estimated the costs of treating self-harm in England as $f 162$ million per year (Tsiachristas et al., 2017). To address this problem appropriately we need to ensure that young people develop self-regulation and coping strategies prior to the onset of stressful life events, such as leaving home, exams and transition to college. Notably, the mean age of first self-harm in this study was 15-16 years, indicating that such prevention interventions would need to happen in secondary schools in order to prevent this behaviour.

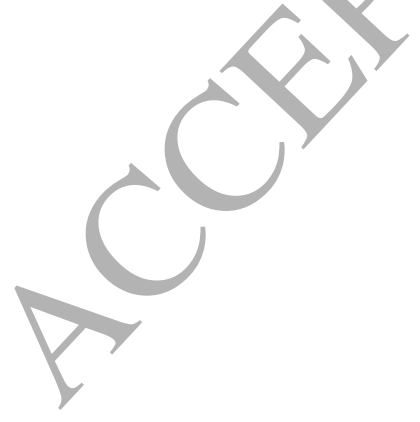


Conforming to many worldwide studies (Herek et al., 2007; Hatzenbuehler et al., 2011; Mortier et al., 2018), sexual minority status considerably increased the likelihood of suicidal behaviour in this population. Furthermore, although there were few in the transgender and non-binary group, all reported past year self-harm, suicidal ideation, and plans, and two of three reported a past year attempt. Small group size means that generalizations cannot be made. Nonetheless, these rates are consistent with research on self-harm and suicidality in gender minority samples, identifying this as a highrisk group.

$\mathrm{NI}$ is currently the only region of the UK where same sex marriage is not permitted, and several studies have found that this population holds more discriminatory views than in other regions of the UK (McAlister, Carr \& Neill, 2014). Also, hate crime against the LGBT community in NI is also noted to be a legacy of the Troubles (O'Neill et al., 2015). It is important to note that the risk of sujcidal thoughts and behaviour in sexual minority groups is lower in countries where attitudes to LGBT people are more tolerant, and where there is less macrosocial structural stigma, there are lower levels of LGBT mental illness (Hatzenbuehler et al., 2014). Raifman, Moscoe, Austin and McConnell (2017) found that the introduction of equal marriage led to a reduction in suicidal behaviour by LGBT young people. These findings further support the need for increased services for people who are LGBT and also the importance of policy change to promote well-being and to prevent suicide in this group.

Another predictor of suicidal behaviour in this study was exposure to childhood adversities, especially intrusive or aggressive adversities, which is unsurprising and concurs with previous research (Bruffaerts et al., 2010, O'Connor \& Nock, 2014; McLafferty et al., 2016). The link between suicide and mental illness is well demonstrated, and in this study both mood and anxiety disorders are particularly associated with an increased likelihood of reporting

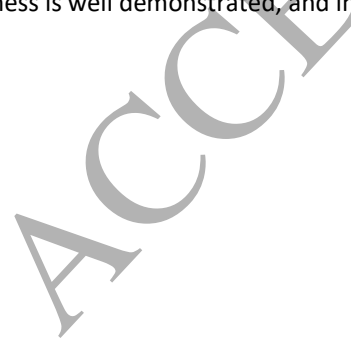


suicidal thoughts and behaviours. Again, policies and strategies to identify, at an early stage, those with profiles that increase their apparent risk, should be prioritised. It would also be useful to identify vulnerable individuals in secondary schools and as they enter college so that they could be offered additional support during this key time.

\section{Limitations:}

Given the link with suicidal behaviour (Gangwisch et al., 2010, Becker et al., 2018), future research and interventions may want to consider sleep disturbances in students. While the study provides important information regarding student mental health and wellbeing, several methodological issues must be acknowledged within consideration of the results. Causality cannot be implied by a cross-sectional study. Assessments of prior suicidal thoughts and behaviours were based on voluntary reports from students. Self-reports of suicidal behaviour and previous attempts varies depending on how the question is asked (single-item assessments of suicide attempt history versus multi item surveys or interviews), although it cannot be concluded which method of report conveys the absolute truth (Hom, Joiner \& Bernert, 2015). Accuracy of participant recall within self-report measures is often a consideration. However, this is not thought to be a major issue in the current study as many of the sample were 21 or younger.

The final consideration relates to the generalizability of the sample. The overall response rate is less than desirable. Response rates on the project internationally range from $7 \%$ to $79 \%$, with a mean response rate of $45.5 \%$ (Auerbach et al., 2018; Mortier et al., 2018). Low response rates have been

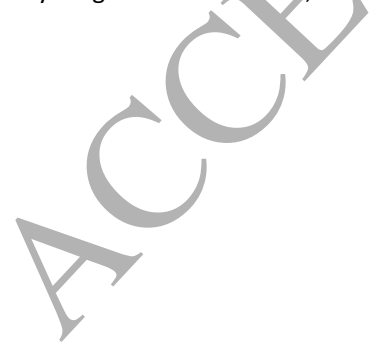


noted by other large-scale college student surveys (Eisenberg et al., 2013). In a meta-analysis of cross-sectional web based surveys, Cook, Heath and Thompson (2000) conclude that response rates average at less than $40 \%$ and note that response rate cannot be equated to generalizability. Prevalence estimates of mental health disorders within this data aligned with both those of UK universities and the Northern Ireland general population (McLafferty et al., 2017). This is reassuring, as is the fact that findings from this sample support those documented amongst college samples worldwide (Mortier et al., 2018) in terms of the vulnerability of those of a sexual minority status. However, generalizability requires caution. As there was a high proportion of females in the current study weights were applied to help address this.

\section{Conclusions:}

Identifying, managing and treating mental illness among college students remains a challenge, and in this study, there was considerable unmet need for mental illness generally. Almost one in five students with a mental health problem said they would not ask for help, and only $10 \%$ received treatment (McLafferty et al., 2017). Stigma around mental illness remains an issue for this group (Yousaf, Grunfeld \& Hunter, 2015; Mclntyre et al., 2014) and it is important that colleges seek creative ways of addressing this problem, perhaps through the use of digital and online interventions, which are already showing some success with this group (Davies, Morriss \& Glazebrook, 2014).

'Declarations of interest: none'. 
Acknowledgments

We thank the Northern Ireland Centre for Stratified Medicine and School of Psychology staff and postgraduate students for assistance with the recruitment during registration week. We also thank the Students Union, Student Support and Student Administration Services at Ulster University, and Inspire Students, for their assistance in this study. We would also like to thank Dr Randy Auerbach and his team at Harvard Students, for their assistance in this study. We would also like to thank Dr Randy Auerbach and his team at Harvard University for their assistance in data management.

\section{Funding}

This research did not receive any specific grant from funding agencies in the public, commercial, or not-for-profit sectors.

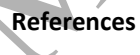

Auerbach, R.P., Alonso, J., Axinn, W.G., Cuijpers, P., Ebert, D.D., Green, J.G., .... Bruffaerts, R. (2016). Mental disorders among college students in the World Health Organization World Mental Health Surveys. Psychological Medicine, 46, 2955-2970.

Auerbach, R. P., Mortier, P., Bruffaerts, R., Alonso, J., Benjet, C., ..... Kessler, R.C. (2018). The WHO World Mental Health Surveys International College Student Project: Prevalence and Distribution of Mental Disorders. Journal of Abnormal Psychology, in press.

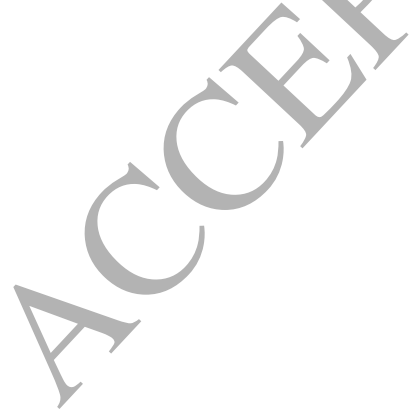


Babor, T. F., Higgins-Biddle, J., Saunders, J., \& Monteiro, M. (2001). The alcohol use disorders identification test. Guidelines for use in primary care. (Second ed.). World Health Organization - Department of Mental Health and Substance Dependence. Retrieved from; http://whqlibdoc.who.int/hq/2001/who_msd_msb_01.6a.pdf Becker, S.P., Dvorsky, M.R., Holdaway, A.S. \& Luebbe, A.M. (2018). Sleep problems and suicidal behaviors in college students. Journal of Psychiatric Research, 99, 122-128.

Björkenstam, C., Kosidou, K. \& Björkenstam, E. (2017). Childhood adversity and risk of suicide; cohort study of 548721 adolescents and young adults in Sweden. BMJ, 357.

Borrill, J., Fox, P., Flynn, M. and Roger, D. (2009). Students who self-harm: coping style, rumination and alexithymia. Counselling Psychology Quarterly, 22, 361-372.

Bruffaerts, R., Demyttenaere, K., Borges, G., Haro, J.M., Chiu, W.T., .... Nock, M.K. (2010). Childhood adversities as risk factors for onset and persistence of suicidal behaviour. British Journal of Psychiatry, 197, 20-27.

Bunting, B., Murphy, S., O’Neill, S. \& Ferry, F. (2013). Lifetime prevalence of mental health disorders and delay in treatment following initial onset: evidence from the Northern Ireland Study of Health and Stress. Psychological Medicine, 42, 1727-1739. 
Cleary, M., Walter, G. \& Jackson, D. (2011). "Not always smooth sailing": mental health issues associated with the transition from high school to college. Issues Ment Health Nurs., 32, 250-254.

Chan, S., Denny, S. Fleming, T., Fortune, S., Roshini, P.J. \& Dyson, B. (2018). Exposure to suicide behaviour and individual risk of self-harm: Findings from a nationally representative New Zealand high school survey. Australian and New Zealand Journal of Psychiatry, 52, 349-356.

Cheng, Q., Li, H., Silenzio, V. \& Caine, E.D. (2014). Suicide contagion: A systematic review of definitions and research utility. PLOS One, 9, e108724.

Cook, C., Heath, F., Thompson, R.L., 2000. A meta-analysis of response rates in Web-or internet-based surveys. Educational and Psychological Measurement, 60, 821-836.

Daly, O.E. (1999). Northern Ireland: The victims. British Journal of Psychiatry, 175, 201-204.

Davies, E.B., Morriss, R. \& Glazebrook, C. (2014). Computer-delivered and web-based interventions to improve depression, anxiety, and psychological wellbeing of university students: a systematic review and meta-analysis. J Med Internet Res., 16, e130.

De Luca, S.M., Franklin, C., Yueqi, Y., Johnson, S., \& Brownson, C. (2016). The Relationship Between Suicide Ideation, Behavioral Health, and College Academic Performance. Community Mental Health Journal, 52(5), 534 -540.

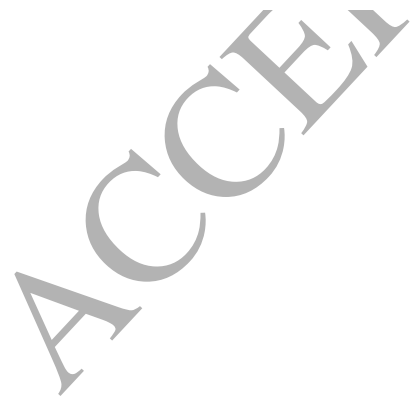


Department of Health, Social Services and Public Safety (2014). Making Life Better: A whole system strategic framework for public health $2013-2023$.

Department of Health, social Services and Public Safety: Belfast. Retrieved from https://www.health-

ni.gov.uk/sites/default/files/publications/dhssps/making-life-better-strategic-framework-2013-2023_0.pdf

Dooley, B.A. \& Fitzgerald, A. (2012). My world survey: national survey of youth mental health in Ireland. Retrieved from: http://researchrepository.ucd.ie/bitstream/handle/10197/4286/My_World_Survey_2012_Online(4).pdf?sequence=1

Eisenberg, D. Hunt, J., \& Speer, N. (2013). Mental health in American colleges and universities: variation across student subgroups and across campuses. The Journal of Nervous and Mental Disease, 20, 60-67.

Fay, M.T., Morrissey, M. \& Smyth, M. (1997). Mapping Troubles-related deaths in Northern Ireland 1969-1998. Initiative on conflict resolution and ethnicity. Belfast: University of Ulster.

Felitti, V. J., Anda, R. F., Nordenberg, D., Williamson, D. F., Spitz, A. M., Edwards, V...... Marks, J. S. (1998). Relationship of childhood abuse and household dysfunction to many of the leading causes of death in adults. The Adverse Childhood Experiences (ACE) Study. American Journal of Preventative Medicine, $14,245-258$.

Franklin, J.C., Ribeiro, J.D., Fox, K.R., Bentley, K.H., Kleiman, E.M., Huang, X., .... Nock, M.K. (2017). Risk factors for suicidal thoughts and behaviors: A metaanalysis of 50 years of research. Psychological Bulletin, 143, 187-232.

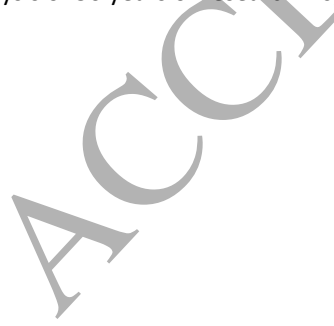


Guan, K., Fox, K.R. \& Prinstein, M.J. (2012). Nonsuicidal self-injury as a time-invariant predictor of adolescent suicide ideation and attempts in a diverse community sample. Journal of Consulting and Clinical Psychology, 80, 842-849.

Gunnell, D., Hawton, K., Ho, D., Evans, J., O'Connor, S., Potokar, J., ....Kapur, N. (2008). Hospital admissions for self harm after discharge from psychiatric inpatient care: cohort study. British Medical Journal, 337, a2278.

Gangwisch, J.E., Babiss, L.A., Malaspina, D., Turner, J.B., Zammit, G.K. \& Posner, K. (2010). Earlier parental set bedtimes as a protective factor against depression and suicidal ideation. Sleep, 33, 97-106.

Garlow, S.J., Rosenberg, J., Moore, J.D., Haas, A.P., Koestner, B., Hendin, H. \& Nemeroff, C.B. (2008). Depression, desperation, and suicidal ideation in college students: results from the American Foundation for Suicide Prevention College Screening Project at Emory University. Depression Anxiety, 25, $482-488$.

Goldman-Mellor, S.J., Caspi, A., Harrington, H., Hogan, S., Nada-Raja, S., Poulton, R., Moffitt, T.E. (2014). Suicide attempt in young people: a signal for long-term health care and social needs. JAMA Psychiatry, 71, 119-127.

Haro, J.M., Arbabzadeh-Bouchez, S., Brugha, T.S., de Girolamo, G., Guyer, M.E., ..... Kessler, R.C. (2006). Concordance of the Composite International Diagnostic Interview Version 3.0 (CIDI 3.0) with standardized clinical assessments in the WHO World Mental Health Surveys. International Journal of Methods in Psychiatric Research, 15(4), 167-180

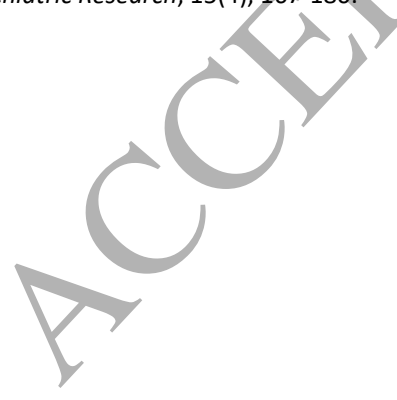


Hatzenbuehler, M.L. (2011). The social environment and suicide attempts in lesbian, gay, and bisexual youth. Pediatrics, $127,896-903$.

Hatzenbuehler, M.L. (2014). Structural stigma and the health of lesbian, gay, and bisexual populations. Current Directions in Psychological Science, 23, 127-132.

Herek, G.M. \& Garnets, L.D. (2007). Sexual orientation and mental health. Annual Review of Clinical Psychology, 3, 353-375.

Hom, M.A., Stanley, I.H. \& Joiner, T.E. Jr. (2015). Evaluating factors and interventions that influence help-seeking and mental health service utilization among suicidal individuals: A review of the literature. Clinical Psychology Review, 40, 28-39.

Hom, M.A., Joiner, T.E. \& Bernert, R.A. (2015). Limitations of a single-item assessment of suicide attempt history: Implications for standardized suicide risk assessment. Psychological Assessment, 28, 1026-1030.

Kearns, H., Forbes, A., Gardiner, M. \& Marshall, K. (2008). When a high distinction isn't good enough: a review of perfectionism and self-handicapping. Australian Educational Researcher, 35, 21-36.

Kessler, R.C., \& Üstün, T.B. (2008). The WHO world mental health surveys: global perspectives on the epidemiology of mental disorders. New York: Cambridge University Press.

Kessler R.C., Amminger, G. P., Aguilar-Gaxiola, S., Alonso, J., Lee, S. \& Ustun, T. B. (2007). Age of onset of mental disorders: a review of recent literature. Current Opinion in Psychiatry, 20, 359-364.

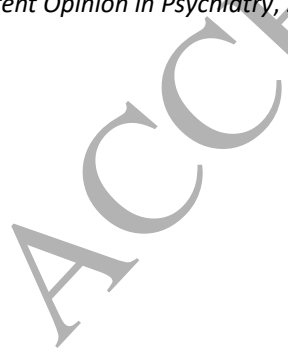


Ma-Kellatns, C., Back, J.H. \& Or, F. (2018). Suicide contagion in response to widely publicized celebrity deaths: The roles of depressed affect, deaththought accessibility, and attitudes. Psychology of Popular Media Culture, 7, 164-170.

McAlister, S., Carr, N. \& Neill, G. (2014). Queering the family: attitudes towards lesbian and gay relationships and families in Northern Ireland. Retrieved from: https://pure.qub.ac.uk/portal/files/11457791/research_update.pdf.

McIntyre, D., Rowland, M., Choi, K. \& Sarkin, A. (2014). Gender differences in the relationships between mental health symptoms, impairment, and treatment-related behaviors among college students. Mental Health and Prevention, 2,80-85.

McLafferty, M., Armour, C., O’Neill, S., Murphy, S., Ferry, F. \& Bunting, B. (2016). Suicidality and profiles of childhood adversities, conflict related trauma and psychopathology in the Northern Ireland population. Journal of Affective Disorders, 200, 97-102.

McLafferty, M., Lapsley, C.R., Ennis, E., Armour, C, Murphy, S., .... O'Neill, S. (2017). Mental health, behavioural problems and treatment seeking among students commencing university in Northern Ireland. Plos One, 12, e0188785.

Mortier, P., Auerbach, R. P., Alonso, J., Bantjes, J., Cuijpers, P., ..... Kessler, R. C. (2018). Suicidal thoughts and behaviors among first-year college students: Results from the WMH-ICS Project. Journal of the American Academy of Child and Adolescent Psychiatry, 57, 263-273. 
Mortier, P., Demyttenaere, K., Auerbach, R.P., Cuijpers, P., Green, J.G., Kiekens, G., Bruffaerts, R. (2017a). First onset of suicidal thoughts and behaviours in college. Journal of Affective Disorders, 207, 291-299.

Mortier, P., Cuijpers, P., Kiekens, G., Auerbach, R.P., Demyttenaere, K., Green, J.G., .... Bruffaerts, R, (2017b). The prevalence of suicidal thoughts and behaviours among college students: a meta-analysis. Psychological Medicine, 14, 1-12.

Mortier, P., Demyttenaere, K., Auerbach, R. P., Green, J. G., Kessler, R. C., Kiekens, G., ... Bruffaerts, R. (2015). The impact of lifetime suicidality on academic performance in college freshmen. Journal of Affective Disorders, 186, 254-260.

Muthén, L. K., \& Muthén, B. O. (1998-2012). Mplus User's Guide (Seventh ed.). Los Angeles, CA: Muthén \& Muthén.

National Institute for Health and Care Excellence (NICE) (2011). Self-harm in over 8s: long-term management. Retrieved from:

https://www.nice.org.uk/guidance/CG133/chapter/1-Guidance\#psychosocial-assessment-in-community-mental-health-services-and-other-specialistmental-health

Nock, M.K., Holmberg, E.B., Photos, V.I., \& Michel, B.D. (2007). The Self-Injurious Thoughts and Behaviors Interview: Development, reliability, and validity in an (2007) adolescent sample. Psychological Assessment, 19, 309-317.

Northern Ireland Statistics and Research Agency (NISRA) (2017). Suicide statistics. Retrieved from: https://www.nisra.gov.uk/publications/suicide-statistics

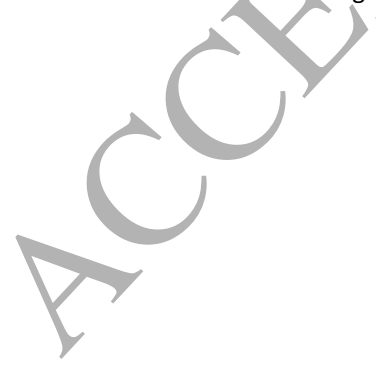


O'Connor, R.C., \& Nock, M.K. (2014). The psychology of suicidal behaviour. Lancet Psychiatry, 1, 73-85.

O’Connor, R.C., Rasmussen, S. \& Hawton, K. (2014). Adolescent self-harm: a school-based study in Northern Ireland. Journal of Affective Disorders, 159, 4652.

O'Connor, R.C. \& O'Neill, S.M. (2015). Mental health and suicide risk in Northern Ireland: a legacy of the Troubles? Lancet Psychiatry, 2, 582-584.

O’Doherty, J. (2016). Outstanding in your field exploring the needs of LGB\&T young people in Northern Ireland. Retrieved from: https://www.rainbowproject.org/Handlers/Download.ashx?IDMF=75981d9c-f647-46bf-86e2-a27b566cfe63.

O'Hara, M. (2013). Through our minds: exploring the emotional health and wellbeing of lesbian, gay, bisexual and transgender people in Northern Ireland. Retrieved from: https://www.rainbow-project.org/Handlers/Download.ashx?IDMF=fce626f4-de30-40d4-bf4f-43dd4afc39ea

O'Neill, S., Corry, C., Murphy, S., Brady, S. \& Bunting, B. (2014). Characteristics of death by suicide in Northern Ireland from 2005 to 2011 and use of health services prior to death. Journal of Affective Disorders, 168, 466-471.

O'Neill, S., Armour, C., Bolton, D., .... \& Murphy, S. (2015). Towards a better future: the transgenerational impact of the Troubles on mental health. Belfast: Northern Ireland Commission for Victims and Survivors, 2015. Retrieved from: https://www.cvsni.org/media/1171/towards-a-better-future-march2015.pdf 
O'Neill, S., Corry, C., McFeeters, D., Murphy, S., Bunting, B. (2016). Suicide in Northern Ireland: An analysis of gender differences in demographic, psychological, and contextual factors. Crisis: The Journal of Crisis Intervention and Suicide Prevention, 37, 13-20.

Paus, T., Keshavan, M. \& Giedd, J.N. (2008). Why do many psychiatric disorders emerge during adolescence? Nature Reviews Neuroscience, 9, $947-957$.

Paus, T., Zijdenbos, A., Worsley, K., Collins, D.L., Blumenthal, J., .... Evans, A.C. (1999). Structural maturation of neural pathways in children and adolescents: in vivo study. Science, $283,1908-1911$.

Raifman, J., Moscoe, E., Austin, S.B. \& McConnell, M. (2017). Difference-in-differences analysís of the association between state same-sex marriage policies and adolescent suicide attempts. JAMA Pediatrics, 171, 350-356.

Reinert, D. F., \& Allen, J. P. (2002). The Alcohol Use Disorders Identification Test (AUDIT): a review of recent research. Alcoholism: Clinical and Experimental Research, 26, 272-279.

Ribeiro, J.D., Franklin, J.C., Fox, K.R., Bentley, K.H., Kleiman, E.M., Chang, B.P. \& Nock, M.K. (2016). Self-injurious thoughts and behaviors as risk factors for future suicide ideation, attempts, and death: a meta-analysis of longitudinal studies. Psychological Medicine, 46, 225-236.

Richardson, T., Elliott, P., Roberts, R. \& Jansen, M. (2017). A longitudinal study of financial difficulties and mental health in a national sample of British undergraduate students. Community Mental Health Journal, 53, 344-352.

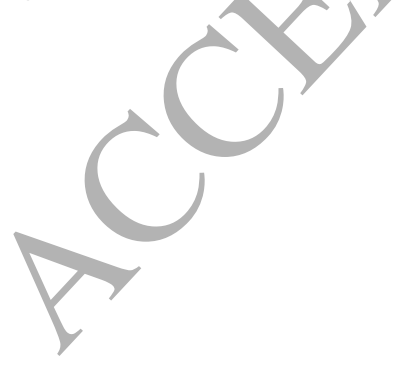


Sadeghi Bahmani, D., Faraji, P., Faraji, R., Lang, U.E., Holsboer-Trachsler, E. \& Brand, S. (2018). Is emotional functioning related to academic achievement among university students? Results from a cross-sectional Iranian sample. Revista Brasileira de Psiquiatria, in press.

Samaritans (2017). Suicide Statistics Report 2017. Retrieved from:

https://www.samaritans.org/sites/default/files/kcfinder/files/Suicide_statistics_report_2017_Final.pdf

Scott, L.N., Pilkonis, P.A., Hipwell, A.E., Keenan, K. \& Stepp, S.D. (2015). Non-suicidal self-injury and suicidal ideation as predictors of suicide attempts in adolescent girls: a multi-wave prospective study. Comprehensive Psychiatry, 58, 1-10

Tsiachristas, A., McDaid, D., Casey, D., .... \& Hawton, K. (2017). General hospital costs in England of medical and psychiatric care for patients who self-harm: a retrospective analysis. Lancet Psychiatry, 4, 759-767.

Universities UK (2015). Student mental wellbeing in higher education / Good practice guide. Retrieved from: http://www.universitiesuk.ac.uk/policy-andanalysis/reports/Documents/2015/student-mental-wellbeing-in-he.pdf

Ursano, R. J., Colpe, L. J., Heeringa, S. G., Kessler, R. C., Schoenbaum, M., \& Stein, M. B. (2014). The Army Study to Assess Risk and Resilience in Service members (Army STARRS). Psychiatry, 77(2), 107-119.

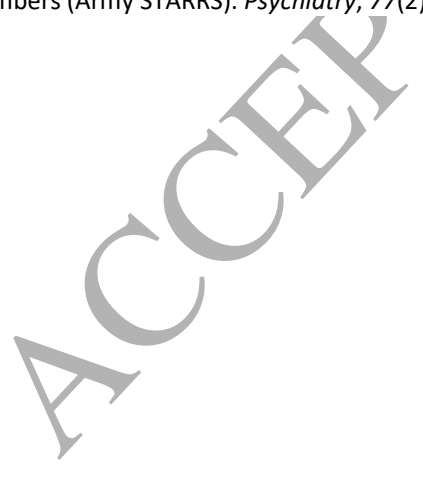


Wilcox, H.C., Arria, A.M., Caldeira, K.M. et al. (2010). Prevalence and predictors of persistent suicide ideation, plans, and attempts during college. Journal of Affective Disorders, 127, 287-294.

World Health Organisation (WHO) (2017). Mental health: suicide data. Retrieved from: http://www.who.int/mental_health/prevention/suicide/suicideprevent/en/ WHO (2015). World Mental Health Surveys International College Student Project (WMHICS). Retrieved from: https://www.hcp.med.harvard.edu/wmh/college_student_survey.php. Yousaf, O., Grunfeld, E.A. \& Hunter, M.S. (2015). A systematic review of the factors associated with delays in medical and psychological help-seeking among men. Health Psychology Review, 9, 264-76.

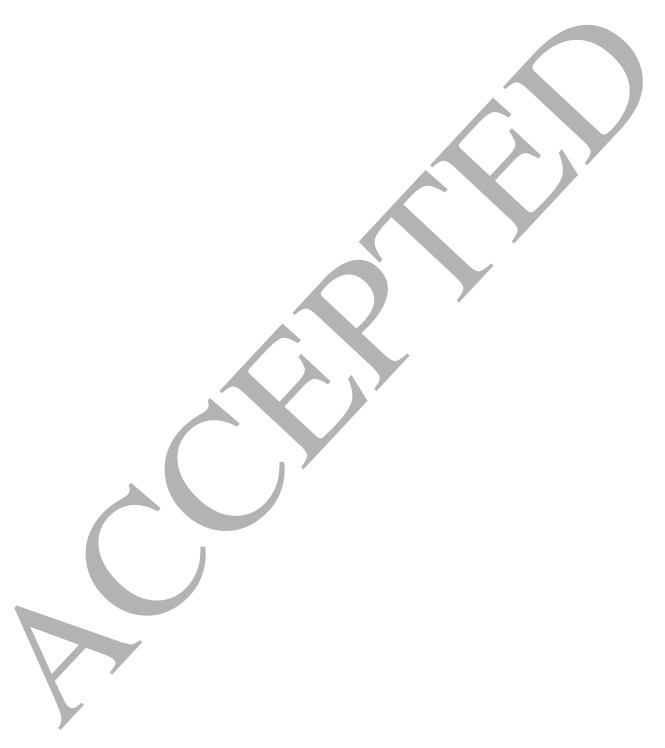



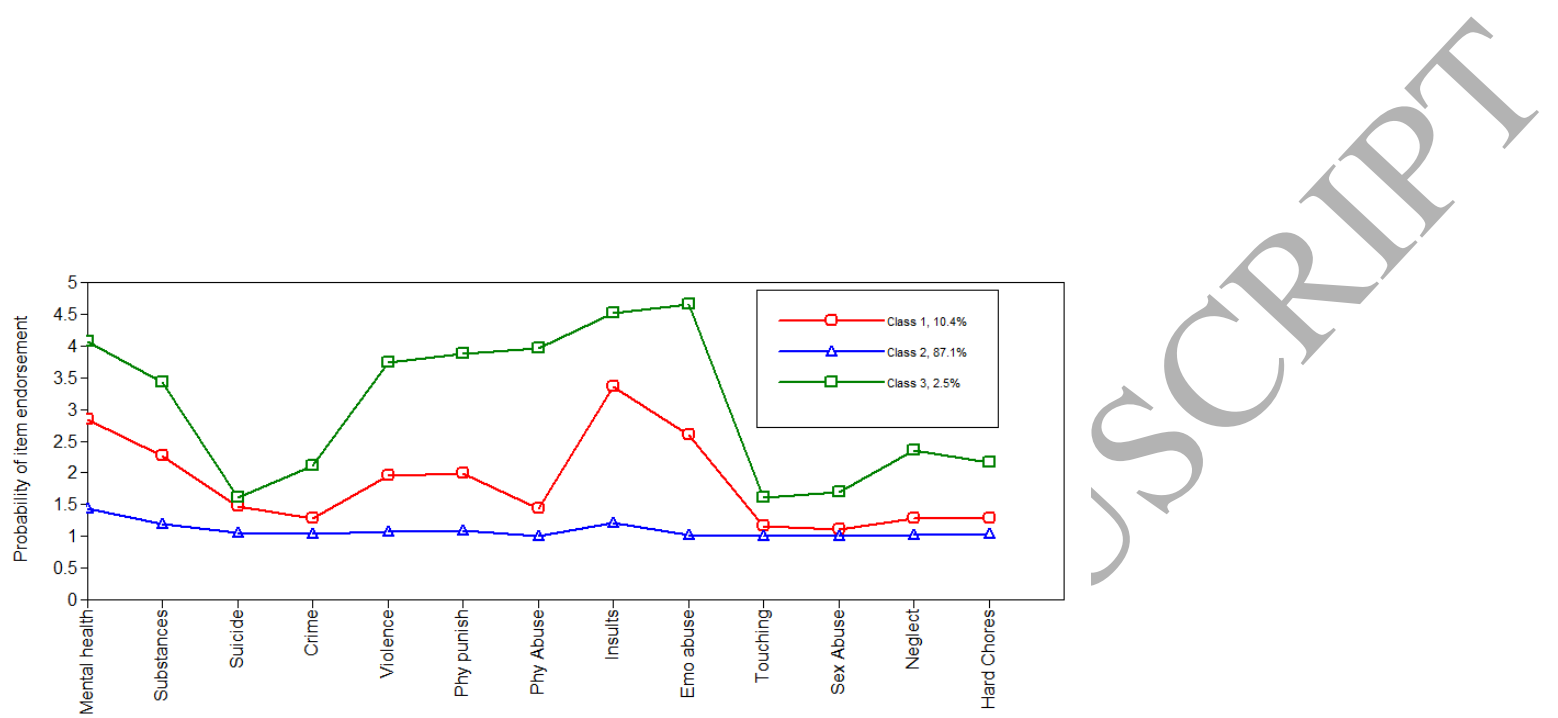

Note: class $1=$ moderate risk, class $2=$ low risk or baseline, class $3=$ high risk

Figure 1. Latent profile plot of childhood adversity indicators

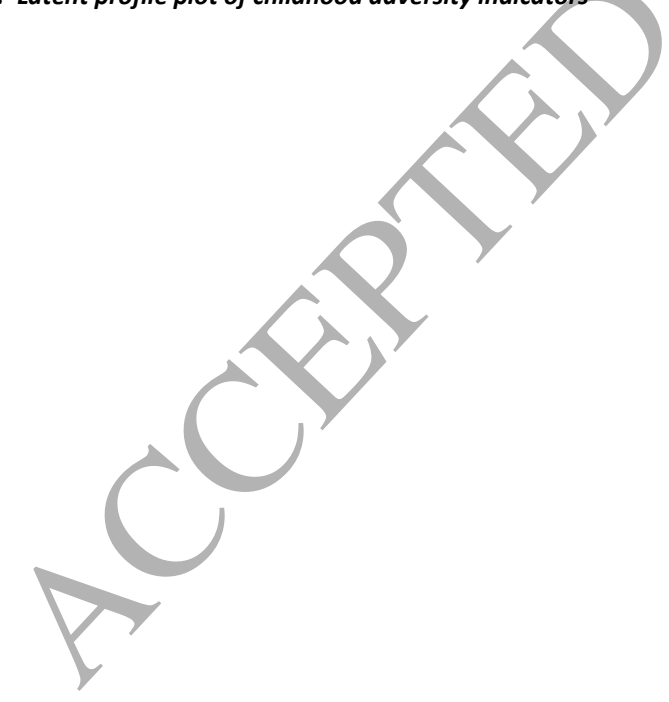


Table 1: Prevalence rates of suicide ideation, plans and attempts in the total sample and among those with ideation in the past 12 months Total Sample 12 month Ideators

\begin{tabular}{ccccccc}
\hline $\mathrm{N}=739$ & Ideation & & Plan & & Attempt \\
& & & & & \\
\hline & & & & & & \\
\hline & & & $n$ & $\%$ & $n$ & $\%$
\end{tabular}

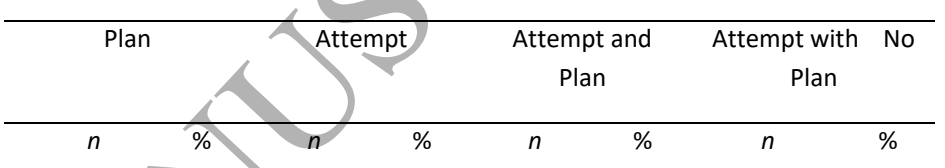

\section{Gender}

\begin{tabular}{|c|c|c|c|c|c|c|c|c|c|c|c|c|c|}
\hline Male & 68 & 24.3 & 46 & 16.5 & 16 & 5.5 & 11.1 & 9 & 3.3 & 9 & 3.3 & 21 & 7.8 \\
\hline Female & 166 & 36.9 & 100 & 21.6 & 42 & 9.0 & 12.2 & 21 & 4.5 & 18 & 3.9 & 38 & 8.3 \\
\hline Other & 3 & 0.4 & 3 & 0.4 & 2 & & 0.4 & 2 & 0.3 & 2 & 0.3 & 1 & 0.2 \\
\hline Total & 237 & 31.0 & 149 & 19.6 & 60 & & 12.1 & 32 & 4.3 & 29 & 3.9 & 60 & 8.2 \\
\hline
\end{tabular}

Note: $n=$ unweighted, $\%=$ weighted, Other = transgender and non-binary

Table 2: Prevalence rates of self harm and suicidality 


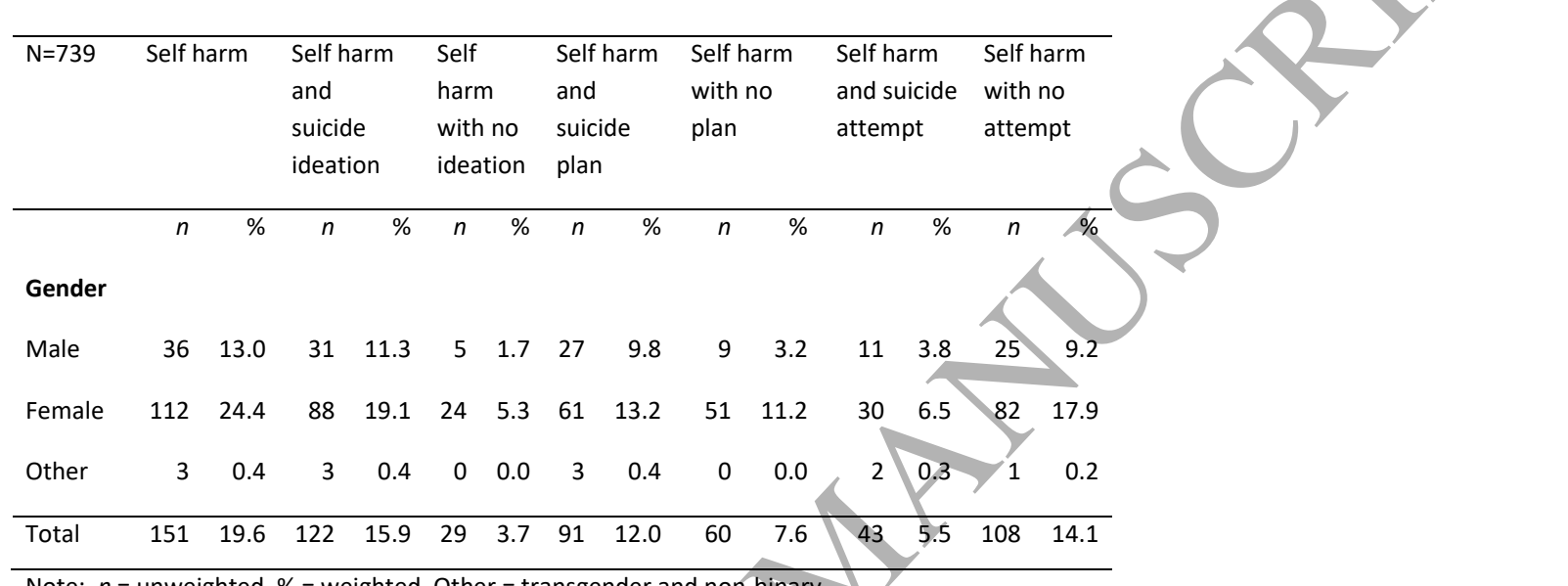

Note: $n=$ unweighted, $\%=$ weighted, Other = transgender and non-binary

Table 3: Prevalence rates of number of times people engaged in self harm

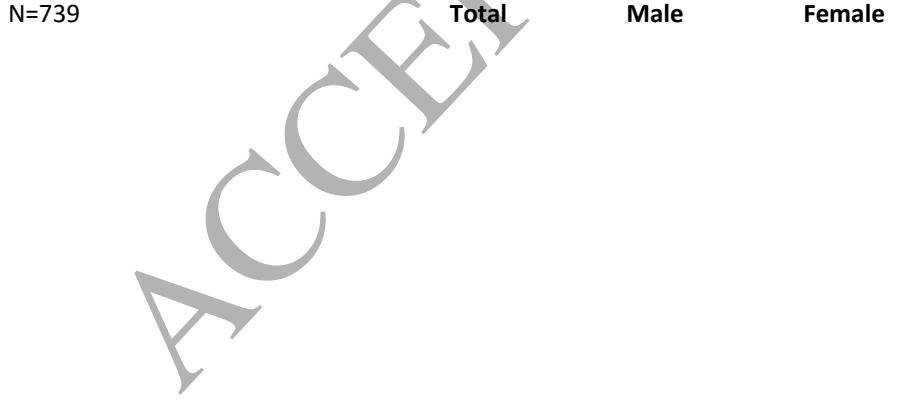




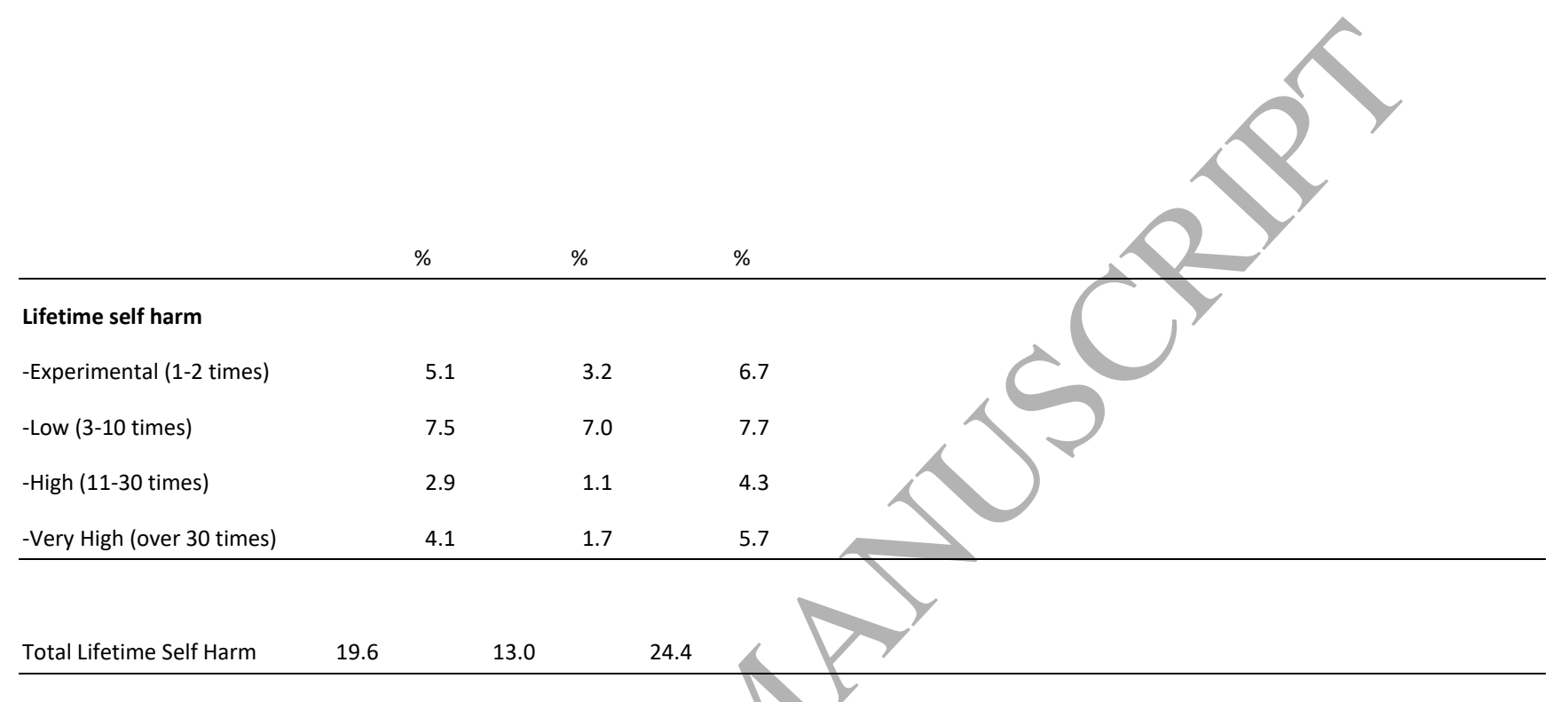

Table 4: Fit indices for Latent Profile Models of childhood adversities 1-4

\begin{tabular}{|c|c|c|c|c|c|}
\hline Model & $\begin{array}{l}\text { Log- } \\
\text { likelihood }\end{array}$ & AIC & SSABIC & Entrophy & LRT (P) \\
\hline 1 & -8250.69 & & 16590.35 & - & - \\
\hline 2 & -6651.76 & & 13440.39 & 1.00 & $3163.61(.53)$ \\
\hline
\end{tabular}




$\begin{array}{lllllll}3 & -5891.37 & 11890.74 & 12138.98 & 11967.52 & 0.99 & 1504.59(.71) \\ 4 & -5325.07 & 10786.16 & 11098.75 & 10882.83 & 0.99 & 1147.10(.68)\end{array}$

Note: AIC = Akaike information criterion, BIC = Bayesian information criterion, SSABIC = sample size adjusted BIC, LRT = Lo-Mendell-Rubin adjusted likelihood ratio test. Optimal model is highlighted in bold

Table 5: Logistic regression analyses of demographic and childhood adversity correlates of suicidal behaviour and self harm

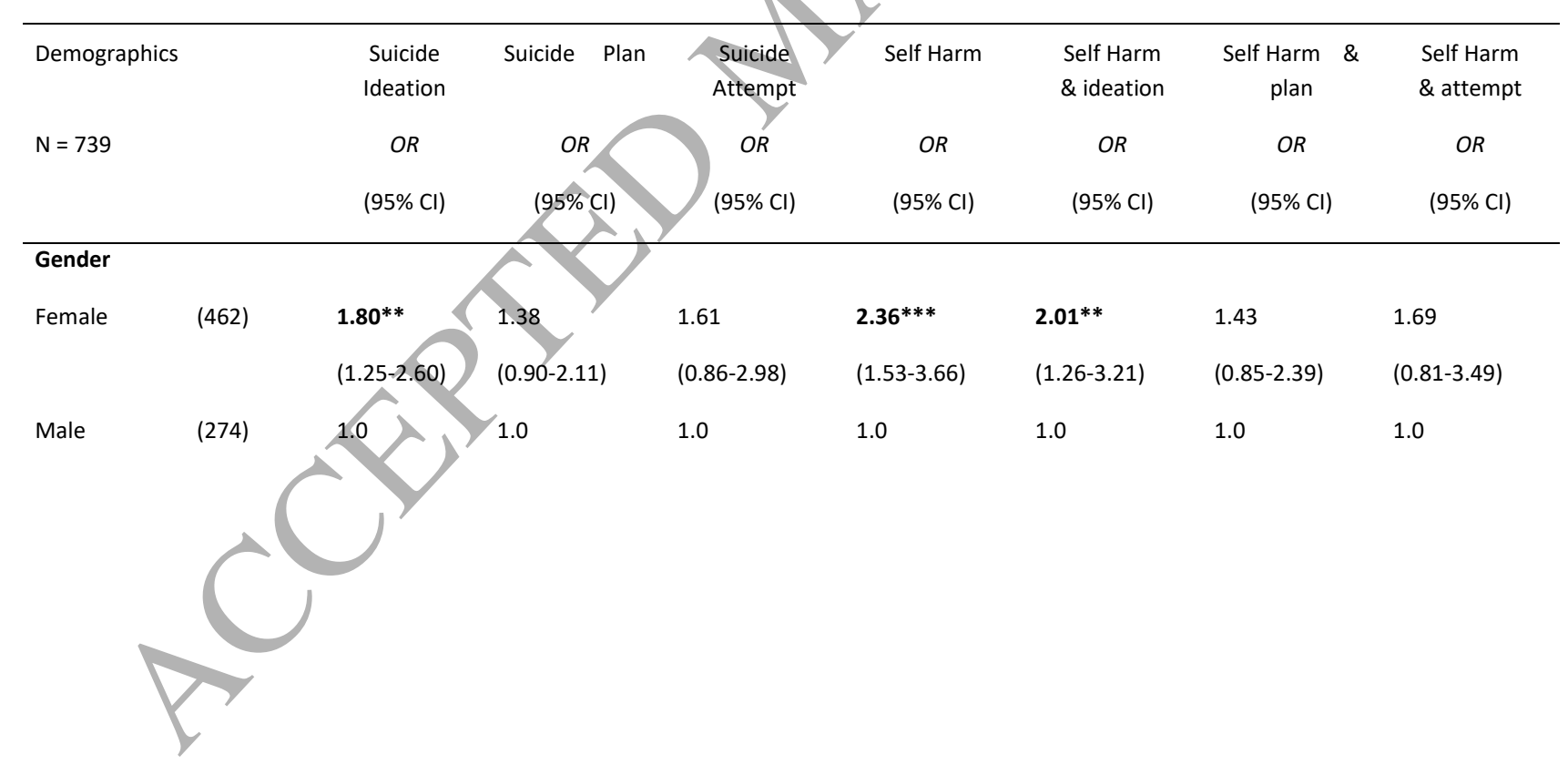


Age

21 and over

(178)

1.26

(0.94-2.28)

2.02*

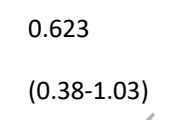

0.88

1.18

(0.85-1.87)

(1.10-3.70)

(0.45-1.28)

(0.50-1.54)

(0.56-2.49)

Under 21

(561)

1.0

1.0

1.0

1.0

1.0

1.0

Sexuality

Non-heterosexual (66)

$\begin{array}{ll}5.37 * * * & 5.93 * * * \\ (3.02-9.53) & (3.39-10.39)\end{array}$

$5.84 * * *$

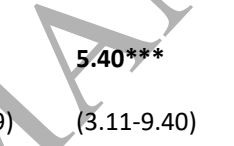

$5.95^{* * *}$

$6.10^{* * *}$

$6.28 * * *$

$(2.96-11.49) \quad(3.11-9.40)$

$(3.38-10.46)$

(3.36-11.08)

(2.94-13.44)

Heterosexual

(669)

1.0

1.0

1.0

1.0

1.0

1.0

\section{Childhood Adversities}

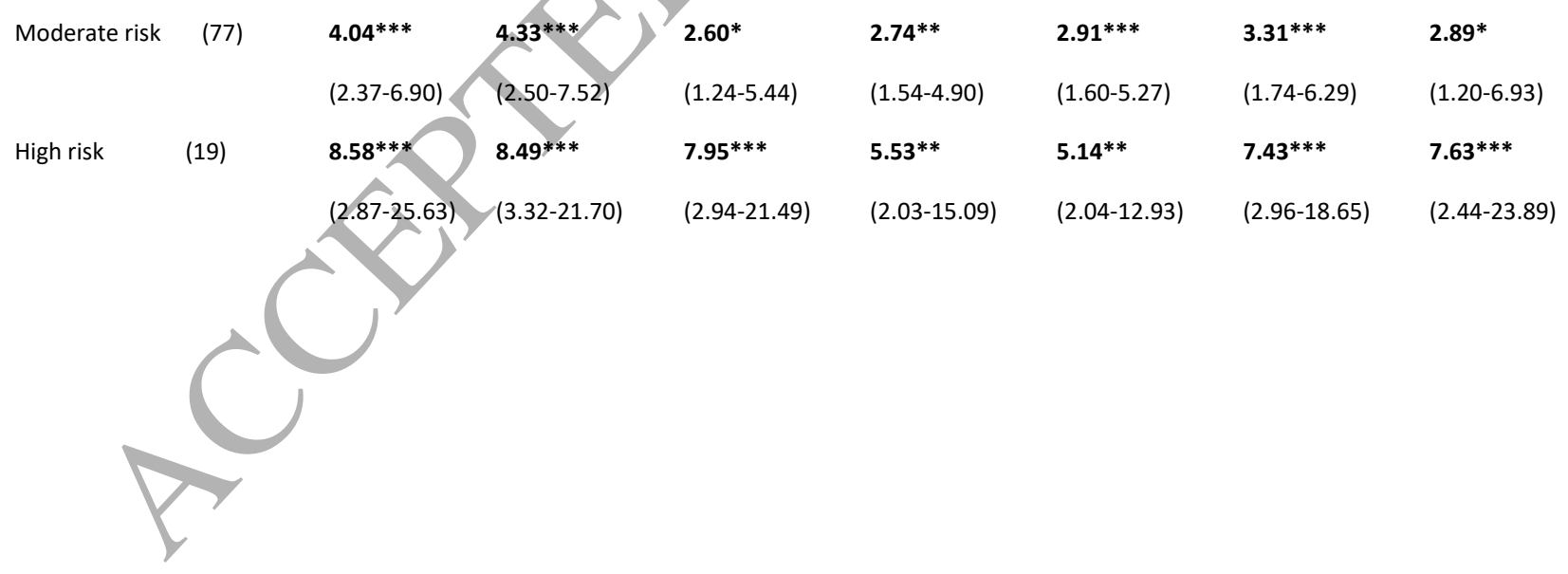




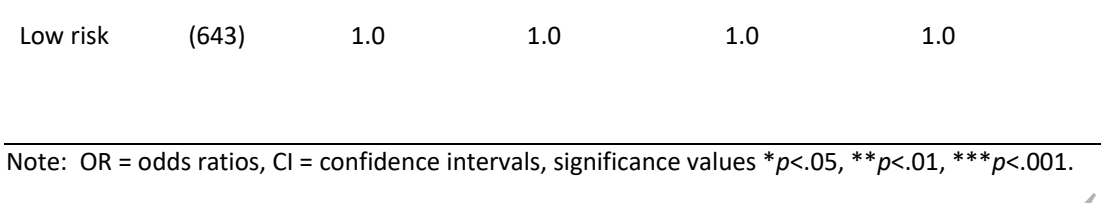

Note: $\mathrm{OR}=$ odds ratios, $\mathrm{Cl}=$ confidence intervals, significance values*p<.05, $p<.01, * * *<.001$.

Table 6: Logistic regression analyses of mental health and substance correlates of suicidal behaviour and self harm

\begin{tabular}{|c|c|c|c|c|c|c|c|}
\hline Demographics & $\begin{array}{l}\text { Suicide } \\
\text { Ideation }\end{array}$ & Suicide & $\begin{array}{l}\text { Suicide } \\
\text { Attempt }\end{array}$ & Self Harm & $\begin{array}{l}\text { Self Harm } \\
\text { \& ideation }\end{array}$ & $\begin{array}{c}\text { Self Harm } \\
\text { plan }\end{array}$ & $\begin{array}{l}\text { Self Harm } \\
\text { \& attempt }\end{array}$ \\
\hline$N=739$ & $\begin{array}{c}\text { OR } \\
(95 \% \mathrm{Cl})\end{array}$ & $\begin{array}{c}\text { OR } \\
(95 \% \mathrm{Cl})\end{array}$ & & $\begin{array}{c}\text { OR } \\
(95 \% \mathrm{Cl})\end{array}$ & $\begin{array}{c}\text { OR } \\
(95 \% \mathrm{Cl})\end{array}$ & $\begin{array}{c}\text { OR } \\
(95 \% \mathrm{Cl})\end{array}$ & $\begin{array}{c}\text { OR } \\
(95 \% \mathrm{Cl})\end{array}$ \\
\hline
\end{tabular}

\begin{tabular}{|c|c|c|c|c|c|c|}
\hline Lifetime mood disorder & $5.65 * * *$ & $4.43 * * *$ & $2.80 * * *$ & $3.85 * * *$ & $4.03 * * *$ & $3.41 * *$ \\
\hline & (3.61-8. & $(2.18-9.01)$ & $(1.75-4.48)$ & $(2.32-6.39)$ & $(2.28-7.14)$ & $(1.52-7.68)$ \\
\hline None & 1.0 & 1.0 & 1.0 & 1.0 & 1.0 & 1.0 \\
\hline
\end{tabular}




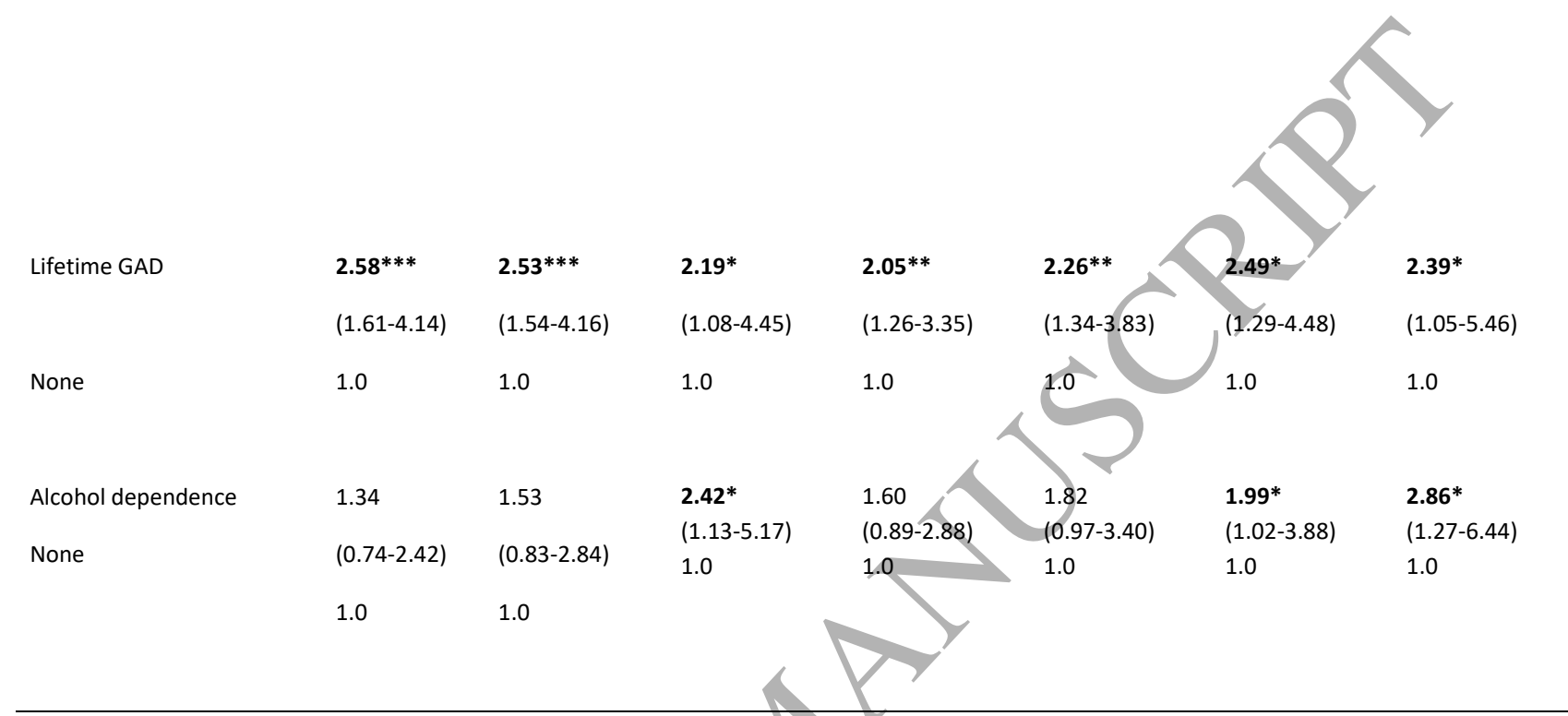

Note: $\mathrm{OR}=$ odds ratios, $\mathrm{Cl}=$ confidence intervals, significance values $* p<.05, * * p<.01, * * * p<.001$. GAD = generalised anxiety disorder Reference category $=$ no disorder

Author statement;

Siobhan O'Neill is the principal investigator on this project and oversees all liaisons on a worldwide basis. She also was the lead author of this paper.

Margaret McLafferty was one of the team responsible for recruitment and data collection. She is also the main analyst for the statistics of this paper.

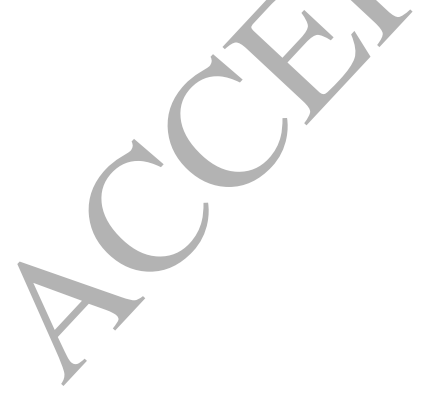


Edel Ennis was responsible for ethical approval of the project, was involved in the data collection and prepared the final version of this manuscript for submission.

Coral Lapsley was one of the team responsible for recruitment and data collection and contributed to the review of the final manuscript.

Tony Bjourson was involved in the design and conceptualisation of this study and contributed to the review of the final manuscript.

Cherie Armour was involved in the design and conceptualisation of this study, supervised the statistical analyses and contributed to the review of the final manuscript.

Sam Murphy supervised data collection and cleaning and contributed to the review of the final manuscript.

Brendan Bunting was involved in the design and conceptualisation of this study and contributed to the review of the final manuscript.

Elaine Murray is the co-principal investigator, was involved in the design and conceptualisation of this study and contributed to the review of the final manuscript.

All authors have approved the final article

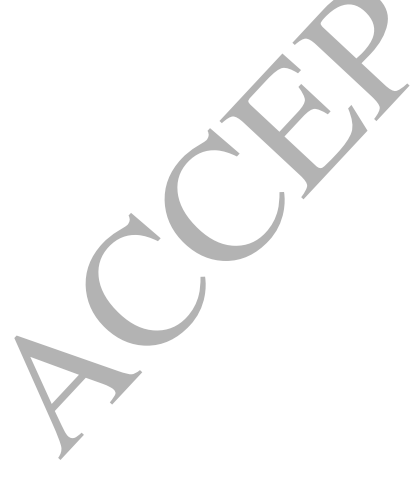

